\title{
Functionalization and Chemical Modification of 2-Hydroxyethyl Methacrylate with Carboxylic Acid
}

\author{
MOHAMMAD HOSSEIN NASIRTABRIZI", L. ZARGIN, \\ S.KHODABANDLOU and S. ROSTAMZADEHMANSOR \\ Department of Chemistry, Ardabil Branch, \\ Islamic Azad University, Ardabil, Iran \\ mhnasirt@yahoo.com
}

Received 7 October 2011; Accepted 3 December 2011

\begin{abstract}
Free radical polymerization of the resulting monomers methyl methacrylate (MMA), ethyl methacrylate (EMA), methylacrylate (MA) and ethylacrylate (EA) with 2-hydroxyethyl methacrylate (HEMA) (in 1:1 mole ratio) were carried out using azobis(isoboutyronitrile) (AIBN) as initiator at the temperature ranges $60-70{ }^{\circ} \mathrm{C}$. The modification of polymers were carried out by 9-anthracenecarboxylic acid (9-ACA) via the esterification reaction between $-\mathrm{OH}$ of poly(HEMA) and - $\mathrm{COOH}$ of 9-ACA, in presence of $N, N^{\prime}-$ dicyclohexyl-carbodiimide (DCC), 4-(dimethylamino) pyridine (DMAP) and $N, N$-dimethyl formamid (DMF). It was found that the molar ratio acid / alcohol/ catalysts $=0.02: 0.02: 0.02$ and 0.002 , optimal for preparation of the ester. As demonstrated by FT-IR, ${ }^{1} \mathrm{H}-\mathrm{NMR}$ and dynamic mechanical thermal analysis (DMTA). The Tg value of methacrylate and acrylate copolymers containing 9-ACA groups was found to increase with incorporation of 9-ACA groups in polymer structures. The presence of 9-ACA groups in the polymer side chains created new polymers with novel modified properties that find some applications in polymer industry. These anthracenic factors could take part in cyclo addition reaction with other factors such as anhydrides and kinons.
\end{abstract}

Keywords: 2-Hydroxyethyl methacrylate, 9-Anthracenecarboxylic acid, Modified polymers, $N, N^{\prime}-$ dicyclohexyl-carbodiimide.

\section{Introduction}

2-Hydroxyethyl methacrylate (HEMA) a hydrophilic, surface active and a high purity dual functionality monomer is widely used in dental adhesive systems and, in its polymeric forms, in numerous biomedical applications ${ }^{1}$. Introducing chemical functionality to polymers provides access to a wide variety of material properties that stem from the functional groups used ${ }^{2}$. Polymers containing carboxylate groups are an interesting research field in polymer and ester chemistry. Attaching the carboxylate groups copolymers chains should lead to important modifications of polymer properties ${ }^{3}$. A number of methods were 
established for the esterification of 9-anthracene-carboxylic acid, but most of them require either acidic or basic medium or the application of heat. The esterification of carboxylic acid with HEMA in the presence of DCC and 4-(dimethylamino) pyridine (DMAP) as catalysts was studied ${ }^{4}$. Literature survey reveals that long chain 9-anthracene-carboxylic acids were not esterified with HEMA in the presence of $N, N^{\prime}$-dicyclohexyl-carbodiimide (DCC). It was observed that (DCC) promotes esterification of alcohols under very mild conditions. All these informations has prompted us to synthesize 9-anthracenecarboxylic esters with an aromatic ring at the side of the ester ${ }^{5-7}$. These anthracenic factors could take part in cyclo addition reaction with other factors such as anhydrides and kinons. The Diels-Alder reaction between anthracene and maleic anhydride to from 9,10-dihydroanthracene-9,10- $\alpha, \beta$-succinic anhydride was successful and occurred via the Diels-Alder mechanism. Anthracene served as the dien and maleic anhydride was the dienophile.

\section{Experimental}

The pure samples 9-anthracenecarboxylic acid (9-ACA), N,N'-dicyclohexylcarbodiimide (DCC), 2-hydroxyethyl methacrylate (HEMA), methyl methacrylate (MMA), ethyl methacrylate (EMA), methylacrylate (MA), ethylacrylate (EA) and 4-(dimethylamino) pyridine (DMAP) were obtained from Merck and distilled under reduced pressure to remove inhibitors befor use. Azobis (isoboutyronitrile) (AIBN) was obtained from Fluka and recrystallized from methanol. $N, N$-dimethyl formamide (DMF;Merck) was dried over anhydrous $\mathrm{MgSO} 4$ for 2days and distilled under reduced pressure. FT-IR spectra were recorded by use of $\mathrm{KBr}$ pellets on a Bruker 4000 spectrophotometer scientific $400 \mathrm{IR} .{ }^{1} \mathrm{H}$ NMR spectra were recorded on a Bruker $250 \mathrm{MHz}$ spectrometer at room temperature, using choloroform- $d$ and dimethyl sulfoxide- $\mathrm{d}_{6}$ as solvent and TMS as internal standard. Dynamic mechanical thermal analysis (DMTA) were characterized by Triton (Tritec $2000 \mathrm{DMN}$ ) with rate $10{ }^{\circ} \mathrm{C} / \mathrm{Min}$.

\section{Synthesis of the copolymers (I-IV)}

Poly(HEMA-co-MMA) (I) or poly(HEMA -co-EMA) (II) or poly(HEMA -co-MA) (III) or poly (HEMA -co-EA) (IV) have been synthesized as general method using $2 \mathrm{~g}$ (20 mmol) of MMA or $2.28 \mathrm{~g}(20 \mathrm{mmol})$ of EMA or $1.73 \mathrm{~g}(20 \mathrm{mmol})$ of MA or $2.00 \mathrm{~g}(20 \mathrm{mmol})$ of EA also a mixture of $2.6 \mathrm{~g}(20 \mathrm{mmol})$ of HEMA and $0.1 \mathrm{~g}(0.6 \mathrm{mmol})$ of AIBN dissolved in 20 $\mathrm{ml}$ of DMF. The reaction mixture was heated to $70 \pm 1^{\circ} \mathrm{C}$, with constant stirring and under a nitrogen atmosphere. The reaction conditions were maintained for $48 \mathrm{~h}$. Copolymer solution were poured drop wise into a large excess of diethyl ether. The precipitated solid was recovered by filtration, washed with diethyl ether and dried in vacuum at room temperature. The reaction condition are shown in Table 1 and Figure 1.

Table 1. The condition of preparation of copolymers.

\begin{tabular}{cccccc}
\hline Sample & Monomer 1 & Monomer 2 & $\begin{array}{c}\text { Amount of } \\
\text { Monomer 1, mmol }\end{array}$ & $\begin{array}{c}\text { Amount of } \\
\text { Monomer2 (mmol) }\end{array}$ & Time, h \\
\hline I & HEMA & MMA & 20 & 20 & 48 \\
II & HEMA & EMA & 20 & 20 & 48 \\
III & HEMA & MA & 20 & 20 & 48 \\
IV & HEMA & EA & 20 & 20 & 48 \\
\hline
\end{tabular}



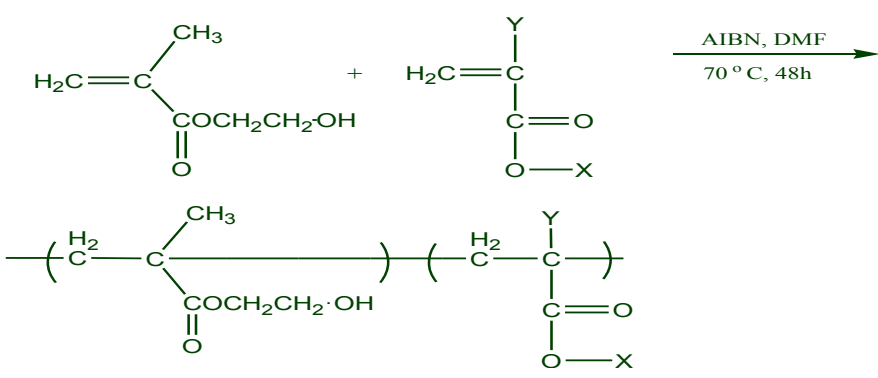

\begin{tabular}{ccccc}
\hline Copolymer & $\mathrm{I}$ & $\mathrm{II}$ & $\mathrm{III}$ & $\mathrm{IV}$ \\
\hline $\mathrm{X}$ & $\mathrm{CH}_{3}$ & $\mathrm{C}_{2} \mathrm{H}_{5}$ & $\mathrm{CH}_{3}$ & $\mathrm{C}_{2} \mathrm{H}_{5}$ \\
$\mathrm{Y}$ & $\mathrm{CH}_{3}$ & $\mathrm{CH}_{3}$ & $\mathrm{H}$ & $\mathrm{H}$ \\
& $\mathrm{MMA}$ & EMA & MA & EA \\
\hline
\end{tabular}

Figure 1. Copolymerization of HEMA with different monomer 4.

\section{${ }^{1}$ H-NMR and FT-IR spectra of polymers (I-IV)}

Poly(HEMA-co-MMA) (I)

FT-IR $(\mathrm{KBr})\left(\mathrm{cm}^{-1}\right)$ : $3440(\mathrm{OH}), 2953-2996$ (aliphatic C-H), 1663 (HEMA C=O), 1732 $(\mathrm{MMA} \mathrm{C}=\mathrm{O}), 1663\left(\mathrm{CH}_{2}\right), 1024-1277(\mathrm{C}-\mathrm{O}) .{ }^{1} \mathrm{HNMR}\left(\mathrm{CDCl}_{3}\right)(\mathrm{ppm}): \delta 0.34-1.3(\mathrm{~s}, 6 \mathrm{H})$, 1.6-2.3 (br, 4H), 2.8-3.1(OH), 3.7 (s, 3H), 3.78-4 ( br, 2H), 4.1-4.3 (br, 2H).

Poly(HEMA -co-EMA) (II)

FT-IR (KBr) $\left(\mathrm{cm}^{-1}\right)$ : $3493(\mathrm{OH}), 2937$ (aliphatic C-H), 1663 (HEMA C=O), 1730 (EMA $\mathrm{C}=\mathrm{O}), 1023-1275(\mathrm{C}-\mathrm{O}) .{ }^{1} \mathrm{HNMR}\left(\mathrm{CDCl}_{3}\right)(\mathrm{ppm}): \delta$ 0.7-1.4 (s, 9H), 1.7-2.2 (br, 4H), 2.8-3 $(\mathrm{OH}), 3.5-3.8$ ( br, 2H), 3.9-4.2 (br, 2H), (br, 2H).

Poly(HEMA -co-MA) (III)

FT-IR (KBr) $\left(\mathrm{cm}^{-1}\right): 3441(\mathrm{OH}), \quad 2928-2952$ (aliphatic C-H), 1665 (HEMA C=O) , 1734 $(\mathrm{MA} \mathrm{C}=\mathrm{O}), 1025-1222(\mathrm{C}-\mathrm{O}) .{ }^{1} \mathrm{HNMR}(\mathrm{DMSO})(\mathrm{ppm}): \delta$ 0.7-1.2 (s, 3H), 1.2-2.2 (br, 5H), 2.8-3 (OH), 3.3-3.5 ( s, 3H), 3.8-4.1 (br, 2H), 4.5-4.7 (br, 2H).

$\operatorname{Poly}(H E M A-c o-E A)(I V)$

FT-IR (KBr) $\left(\mathrm{cm}^{-1}\right): 3429(\mathrm{OH}), 2941$ (aliphatic C-H), 1668 (HEMA C=O), 1731 (EA $\mathrm{C}=\mathrm{O}$ ), 1025-1227 (C-O). ${ }^{1} \mathrm{HNMR}$ (DMSO) (ppm): $\delta$ 0.7-1.2 (s, 6H), 1.5-2.4 ( br, 5H), 2.6$2.8(\mathrm{OH}), 3.4-3.7$ ( br, 2H), 3.8-4.1( br, 2H), (br, $2 \mathrm{H})$.

Attachment of 9-anthracencarboxylat groups to the side chain of the copolymers

In a two-necked flask $4.45 \mathrm{~g}(20 \mathrm{mmol})$ of 9-anthracencarboxylic acid (9-ACA), $4.1 \mathrm{~g}$ (20 $\mathrm{mmol})$ of DCC and $0.25 \mathrm{~g}(2 \mathrm{mmol})$ DMAP were dissolved in $15 \mathrm{~mL}$ of DMF. The flask was cooled until $\quad-5{ }^{\circ} \mathrm{C}$. Then $2.6 \mathrm{~g}(20 \mathrm{mmol})$ of copolymers prepared were dissolved in $15 \mathrm{~mL}$ of DMF and added to the flask mixture at the mentioned temperature. The reaction mixture was vigorously stirred at $-5{ }^{\circ} \mathrm{C}$ for $1 \mathrm{~h}$ and returned slowly to room temperature. The mixture was stirred at room temperature about $24 \mathrm{~h}$ and filtered for remove of white precipitation of $N, N$-dicyclohexyl urea (DCU). Finally, the obtained polymers were poured drop wise into a large excess of $150 \mathrm{ml}$ cold diethyl ether. The precipitated solid was recovered by filtration, washed with diethyl ether and dried in vacuum at room temperature for $48 \mathrm{~h}$ (Figure 2). 

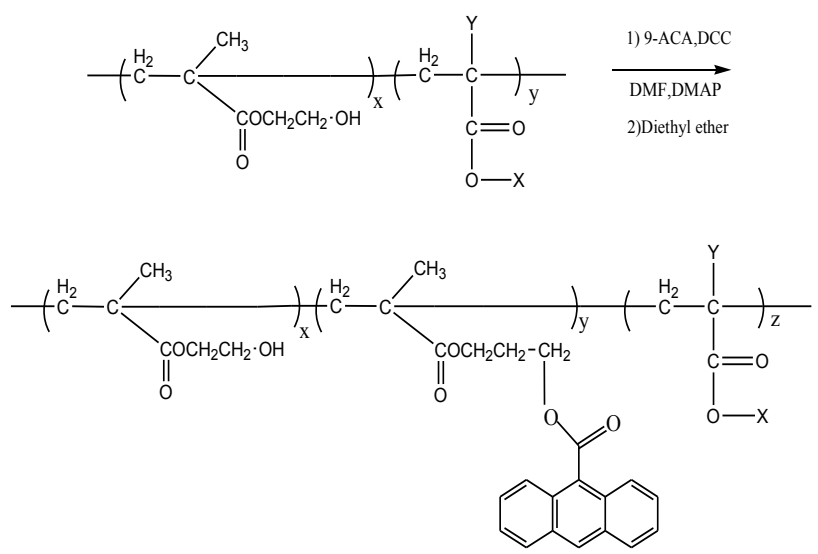

\begin{tabular}{ccccc}
\hline Copolymer & I & II & III & IV \\
\hline $\mathrm{X}$ & $\mathrm{CH} 3$ & $\mathrm{C} 2 \mathrm{H} 5$ & $\mathrm{CH} 3$ & $\mathrm{C} 2 \mathrm{H} 5$ \\
$\mathrm{Y}$ & $\mathrm{CH} 3$ & $\mathrm{CH} 3$ & $\mathrm{H}$ & $\mathrm{H}$ \\
& $\mathrm{MMA}$ & $\mathrm{EMA}$ & $\mathrm{MA}$ & $\mathrm{EA}$ \\
\hline
\end{tabular}

Figure 2. Reaction of copolymers I-IV with 9-ACA.

\section{${ }^{1} \mathrm{H}-\mathrm{NMR}$ and FT-IR spectra of polymers $\left(\mathrm{I}_{\mathrm{ACA}}-\mathrm{IV}{ }_{\mathrm{ACA}}\right)$ after modified}

Poly(HEMA-co-MMA) (I $\left.\mathrm{I}_{A A}\right)$

FT-IR $(\mathrm{KBr})\left(\mathrm{cm}^{-1}\right): 3448(\mathrm{OH}), 3125$ (aromatic C-H), 2927 (aliphatic $\left.\mathrm{C}-\mathrm{H}\right), 1656$ (aromatic $\mathrm{C}=\mathrm{O}$ ), 1728 (ester $\mathrm{C}=\mathrm{O}$ ), 1445 (C=C Ar), -1024-1277 (C-O). ${ }^{1} \mathrm{H}$ NMR (DMSO) (ppm): $\delta$ 0.4-1.3 (s, 9H), 1.6-2.1 (br, 6H), 2.8-3 (OH), 3.5 (s, 3H), 3.7-4.1 ( br, 4H), 4.2-4.5 ( br, 4H), 7.5-8.7 (m, 9H).

Poly(HEMA -co-EMA) (II ACA

FT-IR $(\mathrm{KBr})\left(\mathrm{cm}^{-1}\right)$ : $3422(\mathrm{OH}), 3057$ (aromatic C-H), 2927 (aliphatic C-H), 1648 (aromatic C=O), 1720 (ester $\mathrm{C}=\mathrm{O}), 1452-1560\left(\mathrm{C}=\mathrm{C}\right.$ Ar), 1146-1272 (C-O). ${ }^{1} \mathrm{H}$ NMR (DMSO) (ppm): $\delta$ 0.7-1.2 (s, 12H), 1.4-2.1 (br, 6H), 2.8-3 (OH), 3.8-4.1 ( br, 4H), 4.1-4.3 ( br, 4H), (br, 2H), 7.5-8.7 (m, 9H).

Poly(HEMA -co-MA) (III $A C A)$

FT-IR $(\mathrm{KBr})\left(\mathrm{cm}^{-1}\right): 3412(\mathrm{OH}), 3055$ (aromatic C-H), 2951 (aliphatic C-H), 1667 (ester $\mathrm{C}=\mathrm{O}$ ), 1732 (aromatic $\mathrm{C}=\mathrm{O}), 1446-1562(\mathrm{Ar} \mathrm{C}=\mathrm{C}), 1025-1197(\mathrm{C}-\mathrm{O}) .{ }^{1} \mathrm{H}$ NMR (DMSO) (ppm): $\delta$ 0.7-1.1 (br, 6H), 1.6-2.4 (br, 7H), 2.8-3 (OH), 3.5 ( s, 3H), 4.1-4.2 (br, 4H), 4.3-4.7 (br, 4H), 7.5-8.7 (m, 9H).

\section{$\operatorname{Poly}(H E M A-c o-E A)\left(I V_{A C A}\right)$}

FT-IR (KBr) $\left(\mathrm{cm}^{-1}\right)$ : $3419(\mathrm{OH}), 3127$ (aromatic C-H), 2942 (aliphatic C-H), 1647 (ester $\mathrm{C}=\mathrm{O}), 1726$ (aromatic $\mathrm{C}=\mathrm{O}), 1448-1560(\mathrm{C}=\mathrm{C}$ Ar), 1024-1221 (C-O).

${ }^{1} \mathrm{H}$ NMR (DMSO) (ppm): $\delta$ 0.8-1.14 (s, 9H), 1.7-2.4 (br, 7H), 2.7-2.9 (OH), 3.5-3.7(br, 4H), 3.8-4.2 (br, 2H), 4.2-4.7 (br, 4H), 7.5-8.7 (m, 9H).

\section{Results and Discussion}

Monomer of HEMA was copolymerized with methyl methacrylate (MMA), ethyl methacrylate (EMA), methylacrylate (MA) and ethylacrylate (EA) by free radical 
polymerization in DMF solution. The presence of the hydroxyl group in HEMA leads to modification of HEMA copolymers for various application ${ }^{8}$. The chemical structure of the related polymers are represented in Figures $1 \& 2$.

The resulting polymers are soluble in polar aporotic solvents (e.g. dimethyl formamide, dimethyl sulphoxide) but insoluble in solvents methanol, ethanol, water and diethyl ether. In the past few decades H-NMR spectroscopic analysis has been established as a power tool for the determination of copolymer compositions because of its simplicity rapidity and sensitivity. The assignment of the resonance peaks in the ${ }^{1} \mathrm{H}-\mathrm{NMR}$ spectrum leads to the accurate evaluation of the content of each kind of monomeric unit incorporated into the copolymer chains ${ }^{9,10}$.

The proton resonances of the $-\mathrm{CH}_{3}$ groups in copolymer MMA, EMA, MA and EA at 3.5$3.8 \mathrm{ppm}$ and those the $-\mathrm{CH}_{2}-\mathrm{OH}$ group in HEMA at 3.8-4.1 ppm are clearly resolved. The copolymers compositions were calculated from the H-NMR spectra data. The molar compositions of HEMA and MMA, EMA, MA and EA in copolymers were calculated from the ratio integrated. Let $m_{1}$ be the mole fraction of HEMA and $m_{2}$ is that other monomer. HEMA containing 2 methylen protons and MMA, EMA, MA and EA contains 3 methyl protons. The following expression is used to determine composition of copolymer I-IV (Table 2).

Table 2. Molar percentage of copolymer making monomers.

\begin{tabular}{ccc}
\hline Copolymer & $\mathrm{m}_{1}, \%$ & $\mathrm{~m}_{2,} \%$ \\
\hline Poly(HEMA-co-MMA) & 47 & 53 \\
Poly(HEMA-co-EMA) & 62 & 38 \\
Poly(HEMA-co-MA) & 42 & 58 \\
Poly(HEMA-co-EA) & 48 & 52 \\
\hline Integrared peak area of 3.8- $4.1 \mathrm{ppm}$ & $=\frac{2 \mathrm{~m}_{1}}{3 \mathrm{~m}_{2}}=\mathrm{A}$ \\
\hline Integrared peak area of 3.5-3.8 ppm \\
$\mathrm{m}_{1}+\mathrm{m}_{2}=1$
\end{tabular}

In this work we report the synthesis, characterization and thermal behavior of methacrylic and acrylic copolymers of HEMA without and within 9-ACA groups in the presence of DCC in DMF solution. The resulting modified polymers are soluble in polar aporotic solvents dimethyl sulphoxide but insolvents water and methanol.

In the recent years, studies have been carried out about the attachment of 9-anthracene carboxylic acid to polymers. Also, there are some information about the effects of these groups on the polymers properties. Here is given several types of 9-ACA reaction with different compounds. One of these reaction, is the epoxid ring reaction with 9-ACA, in which produced compound has many applications in the preparation of dielectric thin layers ${ }^{11,12}$. Another reaction of 9-ACA with polymers containing 4-chloromethyl styren, has been investigated. The approach demonstrated in this study facilitates the investigation of the relationship between structure of side-chain groups and polymer properties, providing a general approach for the study of the effect of chemical functionality on material properties of polymers ${ }^{2}$.

But here we have succeded in preparing polymers having side chains containing 9anthracene carboxylate groups the strongly affect the properties of the polymers. There are two ways to introduce functionality to a polymer backbone: polymerization of a prefunctionalized monomer and attachment of functionality to a preformed polymer scaffold via postpolymerization reactions. We chose the second approach, which affords the following three advantages: (a) applicability to a wide variety of functions (while in the first method the modified monomer may unfavorably intervene in the polymerization reaction), (b) ability to create random copolymers with close-to-statistical comonomer distribution by 
copolymerization of similar comonomers (of which one is a functionalizable monomer), thus avoiding "blockiness" that may arise from associative processes of like monomers when very different monomers are copolymerized and (c) ability to use the exact same polymer scaffold for the attachment of different functions, which allows isolation and comparison of the functionality contribution to the polymer behavior ${ }^{2}$.

\section{Charcterization of copolymers I-IV before and after of modification with 9- anthracenecar-boxylic acid:}

\section{Infrared spectra}

The asymmetrical and symmetrical streching due to the methyl and methylen groups in copolymers I-IV are abserved 2953 and $2996 \mathrm{~cm}^{-1}$. The band at $1663 \mathrm{~cm}^{-1}$ is attributed to the ester carbonyl stretching of HEMA and comonomers and $1732 \mathrm{~cm}^{-1}$ is attributed to the ester of comonomers MMA, EMA, MA and EA units. Another band seen at $3440 \mathrm{~cm}^{-1}$ is of the hydroxyl group. The bands of 1024 and $1277 \mathrm{~cm}^{-1}$ is attributed to the ester C-O stretching of HEMA and comonomers MMA, EMA, MA and EA units. For example IR spectra copolymer (HEMA-co-EMA) shown in figure 3a. The infrared spectra of the modified products show the broad bands characteristic of the no reaction hydroxyl groups at wave number $3422 \mathrm{~cm}^{-1}$. Aromatic $=\mathrm{C}-\mathrm{H}$ bonds were appeared at $3057 \mathrm{~cm}^{-1}$. The bands at 1720 and $1648 \mathrm{~cm}^{-1}$ are attributed respectively to the ester carbonyl stretching of HEMA, comonomers MMA, EMA, MA, EA and aromatic ring. For example IR spectra copolymer (HEMA-co-EMA) shown in Figure 3 b.
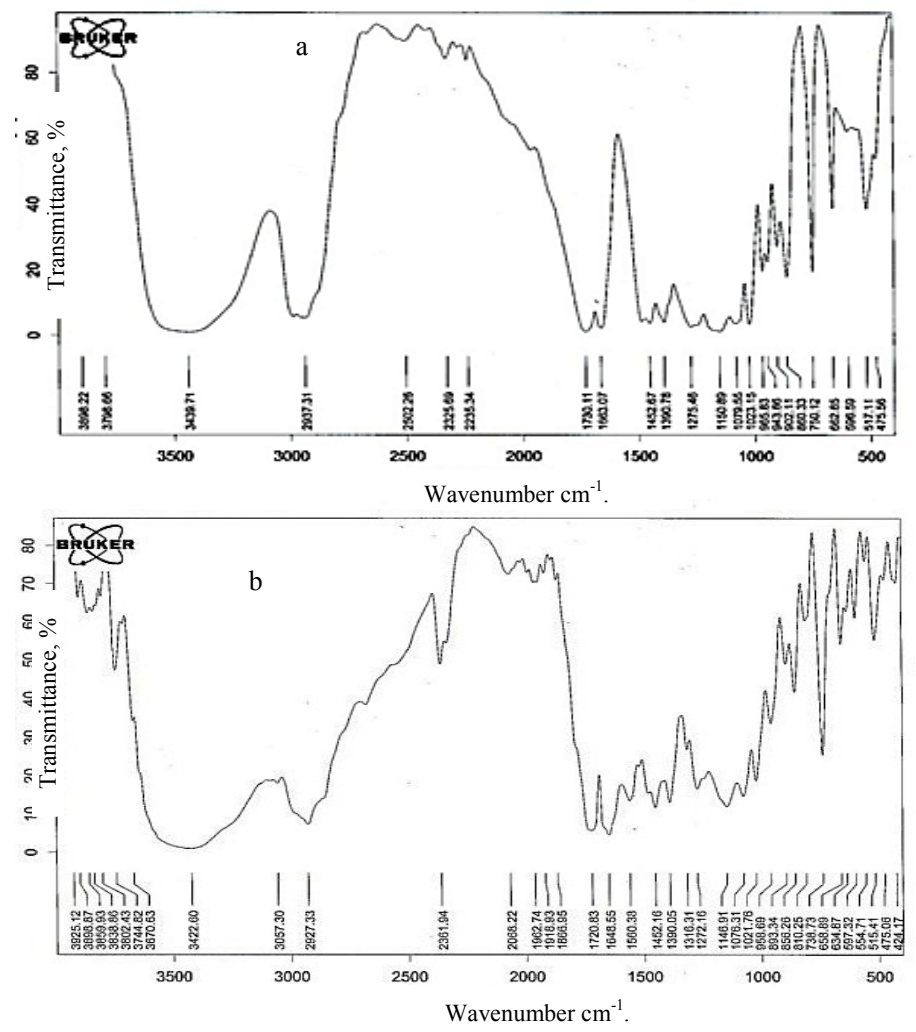

Figure 3. Infrared spectra of poly (HEMA-co-EMA) (a) before reaction with 9-ACA (b) after reaction with 9-ACA. 


\section{${ }^{1} H$-NMR spectra}

${ }^{1} \mathrm{H}$ - NMR spectra of copolymers I-IV showed two signals at 3.9 and $4.2 \mathrm{ppm}$ due to the splitting of methylene protons in the $\mathrm{CH}_{2}-\mathrm{O}$ - group attached to the carbonyl group of the HEMA group. The peak at 1.7-2.2 ppm is due to the methyne proton of hydroxyl group. The resonance signal at 3.5-3.8 ppm was attributed to two methylene protons of $-\mathrm{COOCH}_{2}$ - in copolymer EMA ana EA. The resonance signal at $3.7 \mathrm{ppm}$ was attributed to three methylene protons of $-\mathrm{COOCH}_{3}$ in copolymer MMA ana MA. The broad signal at $0.34-1.3 \mathrm{ppm}$ was due to the methylene groups of backbones and other alkyl groups. For examole H-NMR spectra copolymer (HEMA-co-EMA) shown in figure $4 \mathrm{a}$. The ${ }^{1} \mathrm{H}$ NMR spectra of the pure and modified polymers show the hydroxyl groups $(\delta=2.64-3.24 \mathrm{ppm})$, which are well defined in the unmodified polymers decrease after modification. The peaks at 7.5-8.7 ppm are due to the 9-ACA protons. For example H-NMR spectra copolymer (HEMA-co-EMA) shown in Figure $4 \mathrm{~b}$.
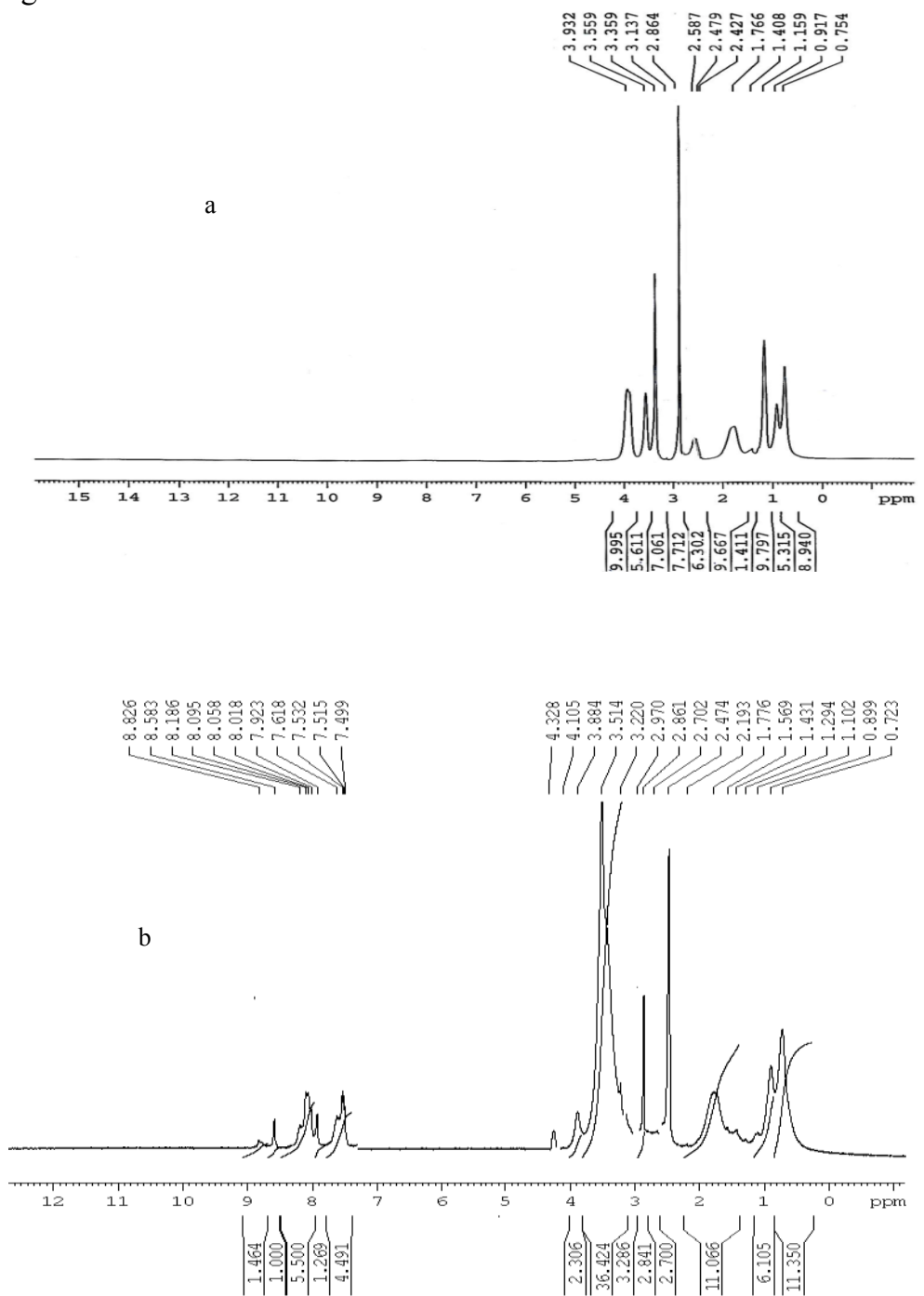

Figure 4. ${ }^{1}$ H NMR spectra of poly (HEMA-co-EMA) (a) before reaction with 9-ACA (b) after reaction with 9-ACA. 


\section{DMTA curve}

The glass transition temperature (Tg) of polymers were determined by Dynamic Mechanical Thermal Analysis (DMTA) Table 3. Glass transition temperature is one of the most essential properties of polymers, dictating important features such as thermomechanical behavior and processing conditions. In the context of microphase separation, for example, reaching the thermodynamically stable, microphase-separated structure requires overcoming the glass transition temperature (Tg) (either by annealing or lowering the Tg by solvent vapor) to allow chain mobility. The DMTA analysis showed that the incorporation of anthracene groups as side chains decrease the free volume of the polymers and therefore, the rigidity and the glass transition temperature (Tg) are increased. DMTA scans show that the presence of bulky 9ACA groups lead to an increase in the Tg of copolymers.

Table 3. Glass transport temperature of polymers.

\begin{tabular}{ccc}
\hline Copolymer & $\mathrm{Tg},{ }^{\circ} \mathrm{C}:$ before modified & $\mathrm{Tg},{ }^{\circ} \mathrm{C}:$ after modified \\
\hline Poly(HEMA-co-MMA) & 17 & 40 \\
Poly(HEMA-co-EMA) & 17 & 37 \\
Poly(HEMA-co-MA) & -14 & 16 \\
Poly(HEMA-co-EA) & -25 & 14 \\
\hline
\end{tabular}

All the synthesized polymers show a single Tg. The higher Tg value of the copolymer I and II than Tg value of the copolymer III and IV are due to the $\alpha$-methyl groups, which facilitate chain entanglement, with increasing steric hindered modification of polymers limited. As can be seen by substitution of steric alkyl in acrylat and methacrylate the temperature of polymer $\mathrm{Tg}$ is increas by modification via 9-ACA. Because increasing steric hindrance, the possibility of esterization of alcoholic group by acid is being decreased. While the antracenic group is joined to these copolymers, the increase in temperature in acrylat and methacrylate copolymers is evident which is greater in methacrylates. This junction of antracenic group is resulted in decreasing the chains vibration, increasing th temperature of modified Tg polymers. By entering the antracenic groups in the structure of polymers, it is possible to achieve new polymers with fully modified $\mathrm{Tg}$ points. These polymers are highly important from view point of new application. DMTA scans show that the presence of bulky 9-anthracene carboxylic acid groups lead to an increasing in the glass transition temperature from $17^{\circ} \mathrm{C}$ to $40{ }^{\circ} \mathrm{C}$ for polymer I, from $17^{\circ} \mathrm{C}$ to $37^{\circ} \mathrm{C}$ for polymer II, from $-14^{\circ} \mathrm{C}$ to $16^{\circ} \mathrm{C}$ for copolymer III and from $-25^{\circ} \mathrm{C}$ to $14^{\circ} \mathrm{C}$ for copolymer IV (Figure 5).

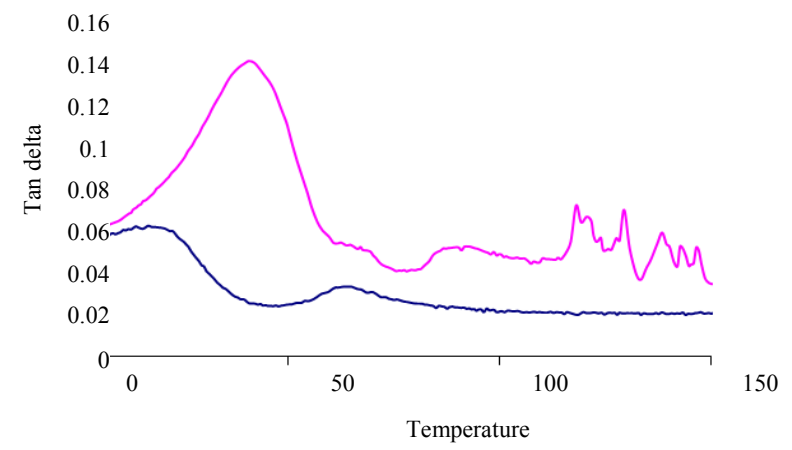

Figure 5. DMTA curves poly (HEMA-co-EMA) (a) before reaction with 9-ACA (b) after reaction with 9-ACA. 


\section{Modulus curve}

Modulus is one of the mechanical properties that demonstrate material's resistance against deformation under load. The flexural modulus (FM), in particular, measures this behavior under simple beam loading. Variation of modulus with temperature for copolymers of HEMA and modified copolymers with 9-anthracene carboxylic acid has been shown in Figure 5. A considerable decrease in modulus observes for modified copolymers I-IV with respect to before modified copolymers of HEMA. It has been proved that, between the temperature of $-50{ }^{\circ} \mathrm{C}$ to $350{ }^{\circ} \mathrm{C}$ in stable slope of $10 \mathrm{~min} /{ }^{\circ} \mathrm{C}$, changes of acrylat and methacrylate polymers have been in case of reaction with 9-ACA and making esteric band. Deletion of hydroxyl group removes the possibility of making hydrogenic relation and results in deduction of polymers solidity (Figure 6). The dynamic properties copolymers of HEMA and its modified with 9-anthracene carboxylic acid at various temperature are summarized in Table 4.

Table 4. Modulus change in synthesized polymers.

\begin{tabular}{lcccc}
\hline \multirow{2}{*}{ Copolymers } & \multicolumn{4}{c}{ Modulus change } \\
\cline { 2 - 5 } & $0{ }^{\circ} \mathrm{C}$ & $25{ }^{\circ} \mathrm{C}$ & $0{ }^{\circ} \mathrm{C}$ & $75{ }^{\circ} \mathrm{C}$ \\
\hline Poly-(HEMA-co-MMA) & 9.99 & 9.82 & 8.61 & 7.55 \\
Poly-(HEMA-co-MMA) with 9-ACA & 9.20 & 8.32 & 6.20 & 6.20 \\
Poly-(HEMA-co-EMA) & 7.01 & 6.35 & 6.05 & 5.37 \\
Poly-(HEMA-co-EMA) with 9-ACA & 5.65 & 5.40 & 3.86 & 2.58 \\
Poly-(HEMA-co-MA) & 6.88 & 4.93 & 4.73 & 4.30 \\
Poly-(HEMA-co-MA) with 9-ACA & 6.31 & 4.66 & 4.24 & 4.07 \\
Poly-(HEMA-co-EA) & 4.32 & 4.19 & 4.08 & 3.98 \\
Poly-(HEMA-co-EA) with 9-ACA & 3.87 & 3.78 & 3.66 & 3.56 \\
\hline
\end{tabular}

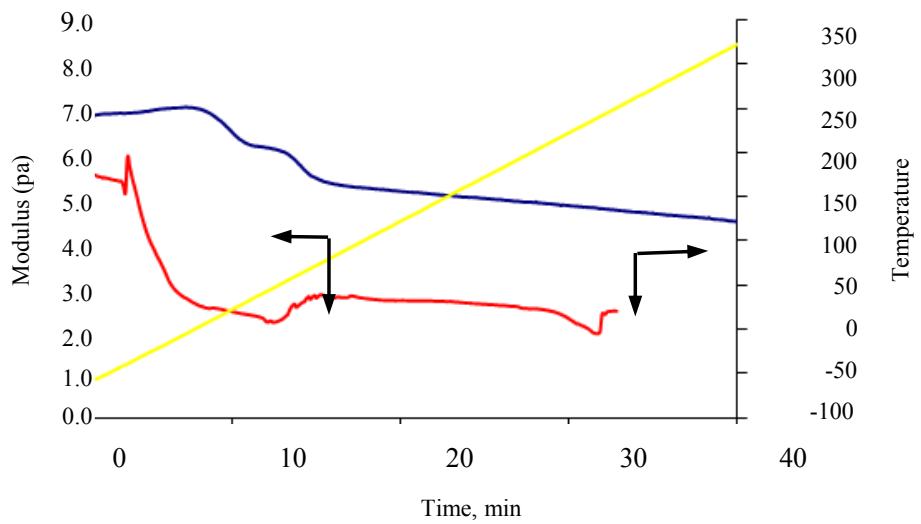

Figure 6. Modulus curves poly (HEMA-co-EMA) (a) before reaction with 9-ACA (b) after reaction with 9-ACA.

\section{Conclusion}

The copolymers of HEMA with different methacrylic and acrylic monomers were synthesized by free radical solution polymerization composition calculated by corresponding H-NMR analysis. HEMA copolymers containing hydroxyl side groups have been modified by 9 -ACA via the esterification reaction in presence of $N, N^{\prime}$-dicyclohexylcarbodiimide (DCC). In these cases, parts of the hydroxyl groups are reacted. Such a dramatic reactivity 
decrease is likely due to the close proximity of the hydroxyl groups, which leads to a close packing of moieties. Study of the glass transition temperature values of the polymers indicated that glass transition temperature values of all the copolymers I and IV increase with incorporation of 9-ACA groups as side chains.

\section{References}

1. Jantas R and Herczynska L, Polym Bull., 2010, 64, 459.

2. Shenhar R, Sanyal A, Uzan O and Vincent M, Rotell Macromol., 2004, 37 , 92.

3. Mahkam M, Assadi M and Mohammadzadeh R, Macromole Res., 2006, 14, 34.

4. Tsvetkova B, Tencheva J and Peikov P, Acta Pharm., 2006, 56, 251.

5. Gacal B, Durmaz H, Tasdelen M.A, Hizal G, Tunca U, Yagci Y and Demirel A.L, Macromole., 2006, 39, 5330.

6. Singh M.D and Ningombam A, Indian J Chem., 2010, 49, 77.

7. Durmaz H, Karatas F, Tunca U and Hizal G, J Polym Sci., 2006, 44, 499.

8. Babazadeh M, Edjlali L and Hajizeynalabedini Z, J Iran Chem Res., 2008, 1, 41.

9. Babazadeh M, Edjlali L and Rashidian L, J Polym Res., 2007, 14, 207.

10. DindarSafa K, Nasirtabrizi M H and Tofangdarzadeh Sh, Iran Polym J., 2008, 17, 39.

11. Puligadda R, Lamb J and Huang R, Anti-Reelective Coating Compositions for use with low k Dielectric Materials., 2003, US pat., 0004283.

12. Enomoto $\mathrm{T}$, Nakayama $\mathrm{K}$ and Puligadda $\mathrm{R}$, Anti-Reflective Compositions Comprising Triazine Compounds., 2004, US pat., 0072420. 


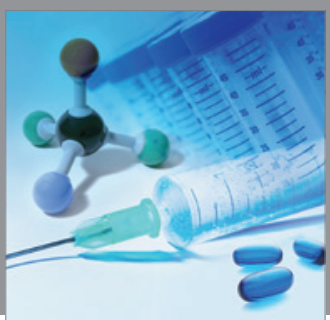

International Journal of

Medicinal Chemistry

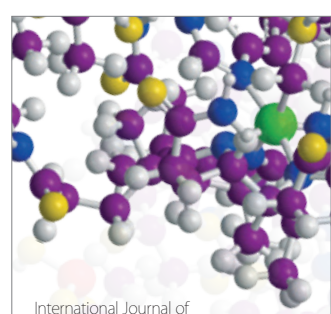

Carbohydrate Chemistry

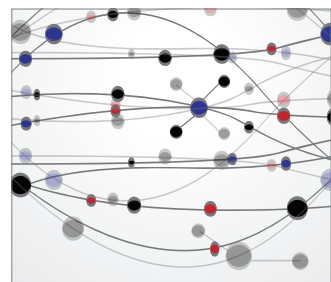

The Scientific World Journal
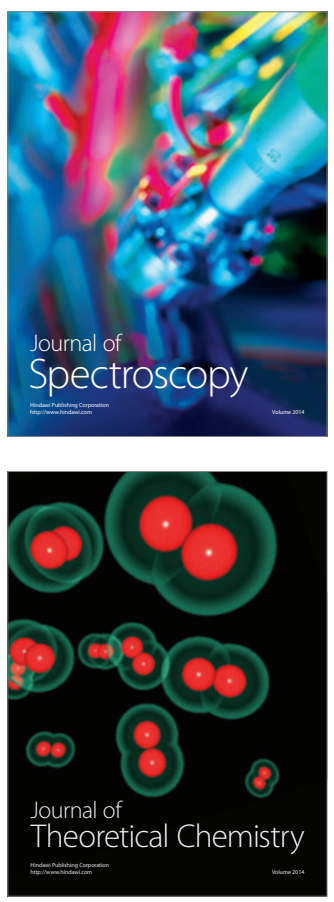
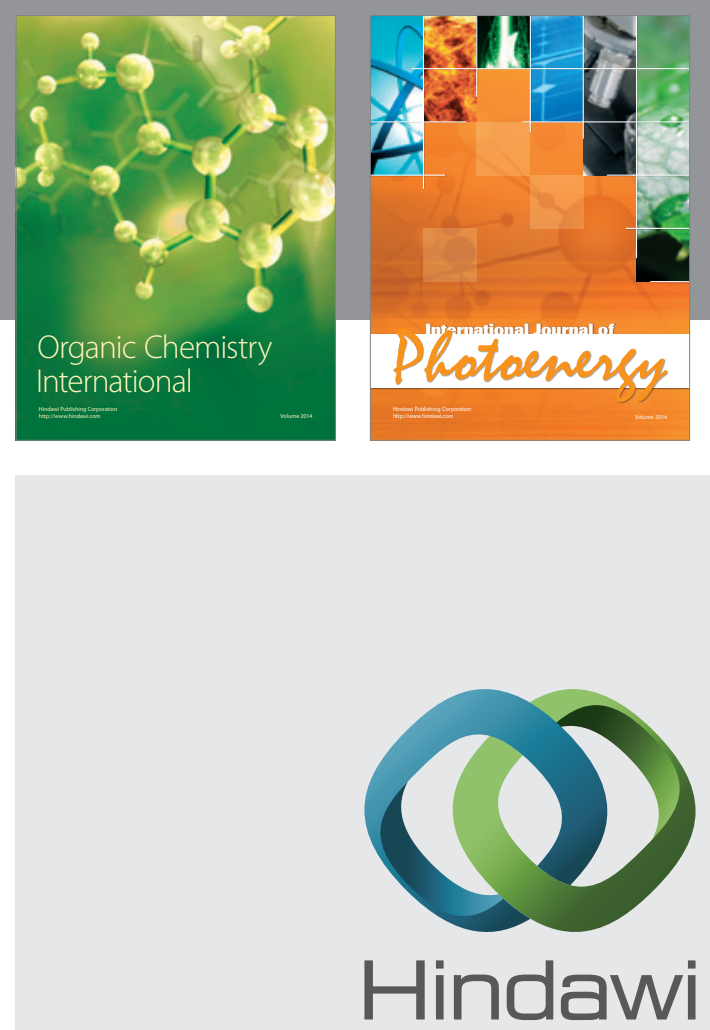

Submit your manuscripts at

http://www.hindawi.com
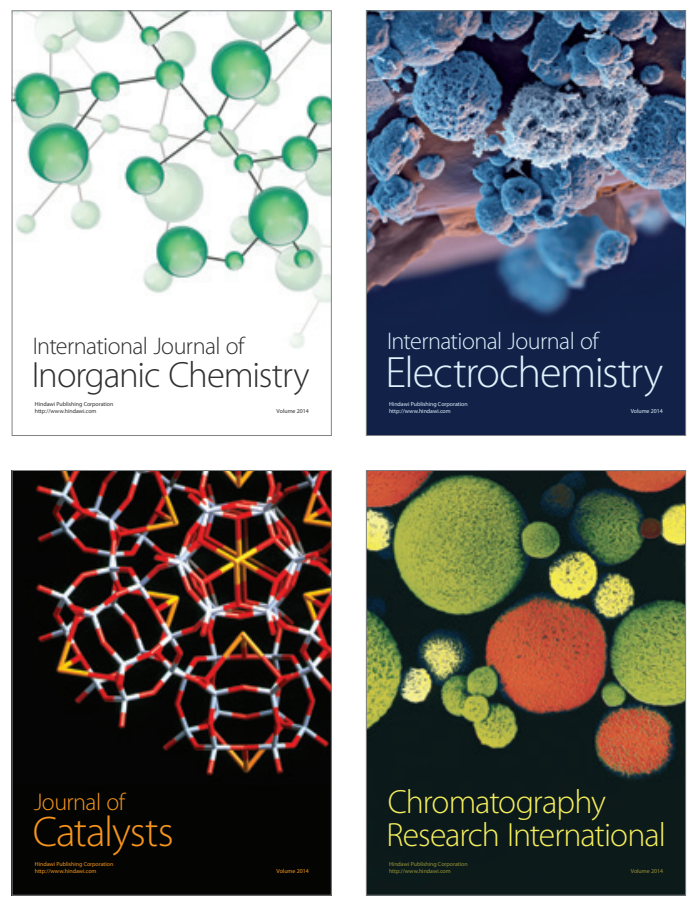
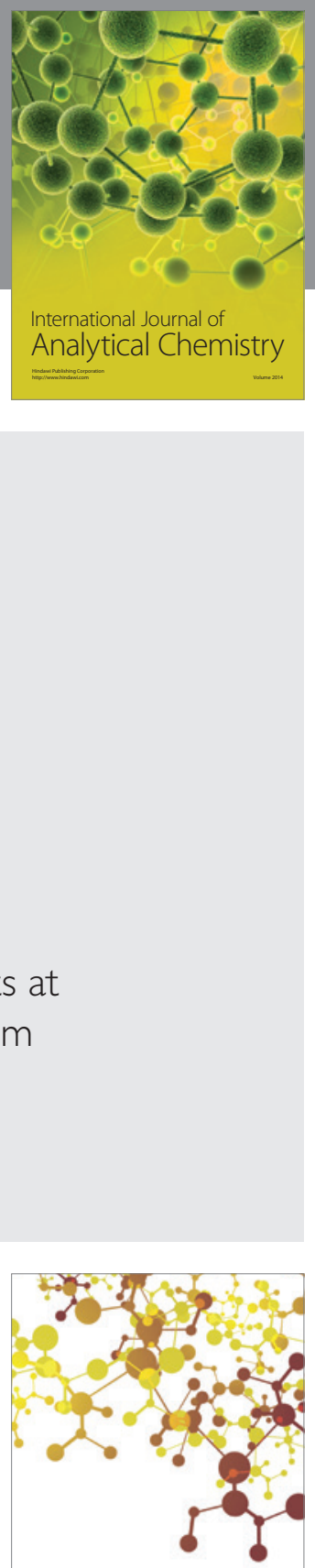

Journal of

Applied Chemistry
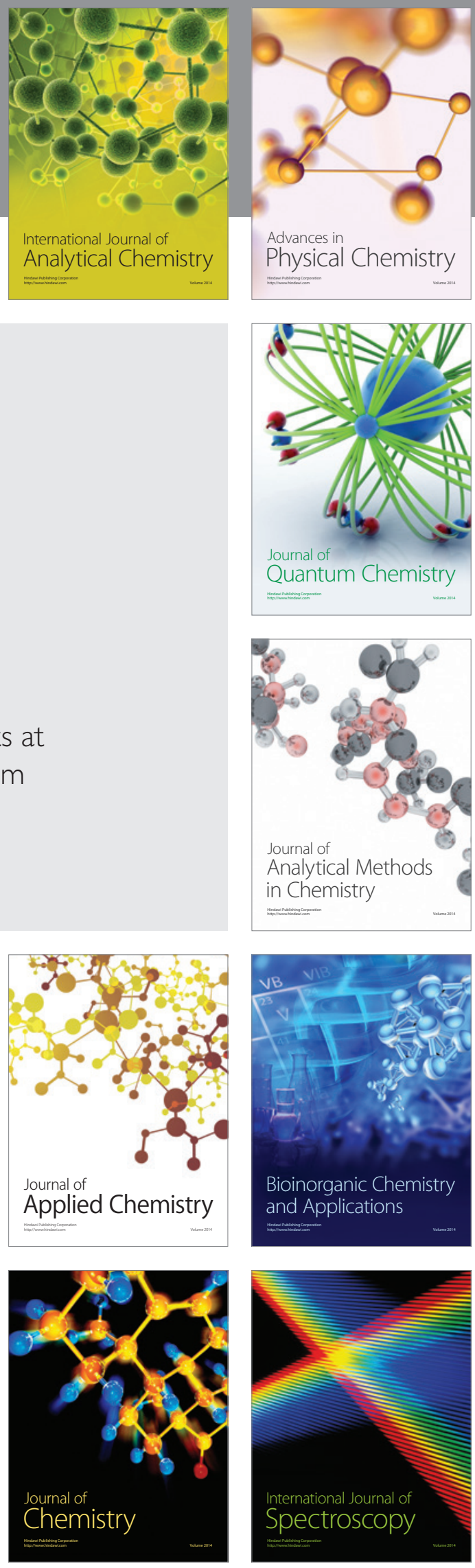